\title{
O Processo de Construção de uma Rede de Atenção em Saúde Mental: desafios e potencialidades no processo de Reforma Psiquiátrica
}

| ${ }^{1}$ Gustavo Zambenedetti, ${ }^{2}$ Claudia Maria Perrone |

Resumo: O objetivo deste trabalho foi investigar como vem sendo o processo de construção da rede de atenção em saúde mental no município de Santa Maria-RS, tendo como foco sua articulação com os ideais da Reforma Psiquiátrica e do SUS. O referencial metodológico utilizado foi o da Pesquisa-Ação Integral e Sistêmica. Os sujeitos da pesquisa constituíram-se por gestores e trabalhadores vinculados à Secretaria de Saúde do município, sendo que a coleta de dados ocorreu a partir da observação participante das reuniōes da Comissão Municipal de Saúde Mental e de entrevistas com informantes. Os dados apontam que o sistema de referência e contra-referência é pouco efetivo e os processos de trabalho são fragmentados, gerando descontinuidade dos tratamentos e desresponsabilização profissional. As estratégias de construção e articulação da rede, pactuadas entre gestores e trabalhadores de saúde, envolvem a implantação de serviços substitutivos, a criação de uma Comissão de Saúde Mental e a capacitação em saúde mental para a atenção básica. Encontramos ainda uma série de estratégias agenciadas no cotidiano dos processos de trabalho, determinando uma rede informal não prevista pela macropolítica de saúde. Problematizamos os efeitos da adequação dos serviços substitutivos ao SUS, assim como os efeitos ambíguos do modo como as estratégias de construção e articulação da rede são efetivadas.

Palavras-chave: Rede; SUS; Reforma Psiquiátrica; saúde mental.

\footnotetext{
${ }^{1}$ Psicólogo, mestrando em Psicologia Social e Institucional, Universidade Federal do Rio Grande do Sul. Endereço eletrônico: gugazam@terra.com.br.

2 Psicóloga, Doutora em Psicologia, professora adjunta, Departamento de Psicologia da Universidade Federal de Santa Maria. Endereço eletrônico: cmperrone@ig.com.br.
}

Recebido em: 06/04/2007. Aprovado em: 10/10/2007. 


\section{Introdução}

Este artigo tem uma temporalidade muito específica. É resultado de uma pesquisa realizada no município de Santa Maria, na região central do Rio Grande do Sul, no ano de 2005. O sentido e a importância do trabalho, para mais além de sua durabilidade no tempo, podem ser resumidos em dois grandes eixos: as dificuldades e ações conceituais e materiais não estão restritas a este município e nem sequer a este estado, pois são da ordem da construção da saúde mental no Brasil; o segundo eixo envolve o que Regina Benevides (2005, p. 24) definiu como o problema de inventar novos modos de fazer acontecer os eixos SUS de universalidade, eqüidade e integralidade. Na saúde mental, essa invenção tem-se traduzido na formação ou criação da rede.

A II Conferência Nacional de Saúde Mental, realizada em 1992, definiu que a atenção integral em saúde mental requer "um conjunto de dispositivos sanitários e socioculturais que partam de uma visão integrada de variadas dimensóes da vida do indivíduo, em diferentes e múltiplos âmbitos de intervenção: educativo, assistencial e reabilitação" (BRASIL, 1992, p. 7). A lei estadual no 9.716 (RS, 1992), que dispõe sobre a Reforma Psiquiátrica no Rio Grande do Sul, aponta alguns desses dispositivos: ambulatórios, emergências psiquiátricas em hospitais gerais, leitos ou unidades de internação psiquiátrica em hospitais gerais, hospitaisdia, hospitais-noite, centros de convivência, centros comunitários, centros de atenção psicossocial, centros residenciais de cuidados intensivos, lares abrigados, pensões públicas comunitárias, oficinas de atividades construtivas e similares.

A idéia de "rede substitutiva" ou "rede integral de saúde mental" passou a ser veiculada com maior intensidade a partir da segunda metade da década de 1980. Segundo Amarante (1995, 1996), esse é o momento em que o Movimento dos Trabalhadores em Saúde Mental (principal ator nas reivindicaçōes pela reforma psiquiátrica) incorpora outros segmentos sociais (grupos de usuários, associações de familiares etc.), configurando-se como "movimento da luta antimanicomial". Esse posicionamento é fortemente influenciado pelo referencial da psiquiatria democrática italiana, que vinha sendo difundido em nosso país desde o final da década de 70 (AMARANTE, 1995). Um dos principais conceitos difundidos por esse referencial é o de "desinstitucionalização", entendido não apenas como desospitalização. Como explicita Melman (2001):

Para a psiquiatria democrática italiana, o processo de desinstitucionalização não podia ser reduzido ao simples fechamento dos velhos, sujos e violentos hospícios. 
Mais do que derrubar paredes, muros e grades, desinstitucionalizar significava desmontar estruturas mentais (formas de olhar) que se coisificam e se transformam em instituições sociais (MELMAN, 2001, p. 59).

O período entre o final da década de 80/início dos anos 90 é marcado pela emergência de uma série de experiências de serviços substitutivos, que visam a responder à complexificação do objeto, que deixa de ser o "doente mental" e passa a ser o "sujeito em sofrimento em relação ao corpo social". Apesar de hoje observarmos manuais (BRASIL, 2004; RS, 2002) e leis (RS, 1992) oferecendo uma série de opções de serviços e modalidades assistenciais, devemos levar em consideração que o processo de produção dessas várias modalidades ocorreu de forma dispersa no tempo e no espaço. As primeiras experiências de CAPS e NAPS remontam às cidades de São Paulo e Santos (GOLDBERG, 1996; BRASIL, 2004a). As primeiras experiências de moradias assistidas remontam a Porto Alegre, Campinas, Santos, Rio de Janeiro (BRASIL, 2004b). E assim por diante.

Historicizar a emergência desses diferentes dispositivos de assistência e os problemas a que cada um responde nos permite desnaturalizar uma certa homogeneidade do que se convencionou chamar rede de atenção em saúde mental, que tende a abarcar um conjunto de serviços, vistos como pontos de uma rede. Esse movimento também aponta o caráter sempre provisório, estratégico e inventivo da rede, ao invés de sua face instituída.

Relatos de experiências (GONÇALVES, 2002; CARVALHO et al., 2004; CABRAL et al., 2002; CASÉ, 2002; SOUZA et al., 2004) nos mostram a existência de inúmeras possibilidades de combinação e articulação entre esses vários dispositivos e ações, gerando diferentes configurações de redes. Estas diferentes estratégias atualizadas na construção da rede de atenção em saúde mental podem envolver a implementação de serviços substitutivos especializados; implementação de ações de saúde mental na atenção básica; construção de práticas como o apoio matricial, a supervisão de casos, e o atendimento conjunto (realizado entre serviços especializados e de atenção básica); criação de equipes volantes, etc.

Tendo em vista essa multiplicidade de combinações possíveis de serviços e ações, assim como a criação ou reprodução de práticas, nossa pesquisa visou a responder à pergunta: como vem sendo o processo de constituição da rede de atenção em saúde mental no município de Santa Maria-RS? 


\section{Metodologia}

Como processo de diferenciação contínua e resistente a uma unificação, era preciso um método que suportasse as irregularidades e a imprevisibilidade presentes em um movimento social como a Reforma Psiquiátrica. Foi utilizado o referencial da pesquisa ação integral e sistêmica, segundo a perspectiva de Morin (2004), que surge a partir da união da pesquisa-ação integral com o enfoque sistêmico. A pesquisa-ação integral pressupõe uma perspectiva de "implicação", tanto por parte do autor/pesquisador (que atuará no sistema de forma a gerar açōes), quanto da parte dos sujeitos da pesquisa/atores (MORIN, 2004).

Não se trata de uma pesquisa sobre a ação, mas de uma pesquisa que visa a transformar a ação e o discurso a partir de uma espiral de revisão que se traduz na ação e no pensamento. A perspectiva sistêmica integra-se à pesquisa ação integral buscando explicitar uma abertura à complexidade do real, visando a uma compreensão do fenômeno complexo que evolui no tempo. Portanto, essa metodologia se preocupa tanto com o processo quanto com o produto, pela ação gerada.

Os sujeitos da pesquisa foram constituídos por gestores vinculados à Secretaria Municipal de Saúde e trabalhadores dos serviços de saúde locais, com foco nos participantes da Comissão Municipal de Saúde Mental (CMSM). Durante o período da pesquisa, 23 pessoas participaram pelo menos de uma reunião da CMSM, representando 16 serviços. Dessas 23 pessoas, havia nove enfermeiros, nove psicólogos, um terapeuta ocupacional, um cientista social, um educador físico, um advogado e um redutor de danos.

Como métodos de coleta de dados, foram realizadas observaçôes participantes das reuniōes da Comissão Municipal de Saúde Mental, entre os dias 2 de junho a 28 de setembro de 2005, totalizando 11 reuniōes; entrevista com informantes, as quais foram gravadas e transcritas; e coleta de documentos (atas de reuniōes e plano municipal de saúde mental). As entrevistas com informantes tiveram por objetivo aprofundar algumas discussões e levantar aspectos históricos em relação à constituição dos serviços da rede de saúde mental. Estas foram realizadas com um gestor municipal e um representante de cada serviço da chamada rede de saúde mental: um profissional da atenção básica, do ambulatório de saúde mental, do CAPSad, da unidade psiquiátrica, da unidade de redução de danos. O CAPS II não indicou nenhum representante. 
Seguindo a proposta metodológica, que enfatiza o acompanhamento de um processo e a participação do pesquisador no mesmo (e não o mero mapeamento de uma situação "estanque" por um pesquisador exterior ao processo), a apresentação dos resultados da pesquisa acompanhará a discussão dos mesmos, fugindo da tradicional compartimentalização entre apresentação dos resultados e discussão. Isso se justifica na medida em que a discussão dos dados foi sendo realizada junto aos atores da pesquisa, ao mesmo tempo em que ela foi se desenrolando no tempo.

\section{Análise e discussão dos dados}

A partir da análise do processo investigado, constatamos a presença de três importantes momentos na construção da rede de atenção em saúde mental: a implantação dos serviços substitutivos; a constituição da Comissão de Saúde Mental; a construção de um processo de capacitação e descentralização em saúde mental para a atenção básica.

\section{A saúde mental no município de Santa Maria: o impacto do processo de Reforma Psiquiátrica e a implantação dos serviços substitutivos} Santa Maria é um município com uma população de 243.611 mil habitantes ${ }^{1}$. A área do município é de $1.823,1 \mathrm{~km}$. A renda per capita é de $\mathrm{R} \$ 8.864 /$ ano e o setor terciário absorve $80 \%$ da população economicamente ativa ${ }^{2}$.

Segundo Crasoves (1994), no início da década de 80 toda a atenção em saúde mental era direcionada ao hospital psiquiátrico localizado no município, que em 1982 foi transferido para o Hospital Universitário, tornando-se uma ala deste. A autora chama a atenção para a inexistência de dispositivos extra-hospitalares de assistência e para o trabalho isolado e sem interação com outras instituições, realizado pela ala de psiquiatria do Hospital Universitário.

No plano político, o impacto do processo da Reforma Psiquiátrica começou a ocorrer ainda no final da década de 80, com a realização do I e II Simpósios Internacionais de Saúde Comunitária, organizados pelo Departamento de Psicologia da Universidade Federal de Santa Maria (UFSM). Em 1993 foi criado o SAISM (Serviço de Atenção Integral à Saúde Mental), a partir da iniciativa de um grupo de professores e profissionais do Departamento de Psicologia da UFSM, que se propôs a viabilizar a lei estadual da Reforma Psiquiátrica, aprovada no ano anterior em nosso estado. Esse serviço acabou sendo extinto alguns anos 
depois, por falta de sustentação político-administrativa (dificuldade na articulação com a Secretaria de Saúde, falta de profissionais e de condições de funcionamento adequadas). Apenas em 1997 a Prefeitura começou a chamar profissionais concursados para a constituição de uma equipe de saúde mental, que passou a desenvolver atividades ambulatoriais junto à sede do COMEN (Conselho Municipal de Entorpecentes).

Em 2001 ocorreu a implantação do Serviço de Saúde Mental da Secretaria de Saúde do município, também conhecido como Ambulatório de Saúde Mental, que passou a ser referência para a atenção básica do município.

Segundo informações fornecidas pela gestão municipal, o período entre 2001 e 2003 foi marcado por um grande empenho para a implantação dos CAPS, dispositivo que se constituiu na aposta da gestão naquele momento e que visava a alterar a "lógica" da atenção no campo da saúde mental: "E aí se investiu muito na questão dos CAPS para mudar toda uma lógica de atendimento, porque o ambulatório não era e não é resolutivo até hoje" (gestor 1).

Os projetos de CAPS II e CAPSad foram formulados com a participação de trabalhadores do ambulatório de saúde mental, sendo que alguns passaram a constituir as equipes dos novos serviços, implantados respectivamente em 2002 e 2003. Em relação a esse período e à constituição dos CAPS, é interessante a fala de uma trabalhadora que expressa certa angústia diante da "zona de indeterminação" criada entre a macropolítica (as leis, portarias, diretrizes da Reforma Psiquiátrica) e o modo como ela é implementada no cotidiano: "De dentro do ambulatório saiu o CAPS álcool e drogas e o CAPS Prado Veppo. Ele (o CAPSad) foi para o COMEN e começou a atender nos moldes dele, porque não sabiam como funcionava um CAPS" (profissional A).

Um dos motivos que moveu a implantação desses serviços foi a pressão exercida por trabalhadores em função da grande demanda em saúde mental.

a gente está implantando os serviços porque, tem hora que tu te vê sufocada, encurralada por uma cobrança muito grande, tu entra no embalo dos trabalhadores de estarem cobrando a necessidade de ter essas referências. E aí tu termina realmente, até porque existe também uma iniciativa do governo federal e tal, indo atrás e então vamos envolver, vamos pensar num projeto, vamos estar pensando em implantar mais dois serviços, porque a gente é muito cobrado até a nível regional "ah, Santa Maria tem capacidade para ter cinco CAPS (gestor 1). 
Em período posterior, entre 2004/2005, observaram-se os efeitos da entrada destes dispositivos na oferta de serviços do município. Um dos efeitos esperados a redução da demanda para o ambulatório de saúde mental - não ocorreu. A demanda do ambulatório continuou crescendo, assim como a demanda para os novos serviços, que logo começaram a funcionar acima da capacidade prevista.

Por exemplo, uma consulta médica, hoje, tu só consegue para metade de janeiro de 2006. E a consulta de psicologia, uma ficha, uma triagem, tem ali uma ficha de espera que acho que vai para metade do ano que vem. Então está tudo lotado (setembro/2005, profissional D).

Tendo em vista a perspectiva de gestores e trabalhadores, a rede é estabelecida a partir da constituição de serviços e por uma dinâmica de circulação dos usuários pelos serviços de saúde, a partir de encaminhamentos que seguem o princípio de hierarquização, conforme disposto no SUS. Nessa perspectiva, os profissionais acreditam que

a formação de rede é por exemplo, o paciente em crise, ele interna, fora de crise ou em alguma outra situação intermediária vá para o CAPS, numa outra situação para o PSF. Então pensar rede é pensar em várias instâncias de atenção à pessoa. E daí quando eu penso isso, eu penso que os profissionais devem trabalhar muito assim, de forma que tenha uma comunicação e troca no trabalho. E isso a gente não tem, é difícil. (profissional $\mathrm{C}$ ).

Essas várias instâncias de tratamento exigem fluxo e circulação de informações e pessoas, expressos sobretudo pela referência e contra-referência. No entanto, as discussões da Comissão de Saúde Mental e as falas dos diversos entrevistados apontaram que o sistema de referência e contra-referência não era efetivo. Ocorria pouca circulação de informações, de maneira que os profissionais muitas vezes desconheciam a existência dos serviços que compõem a rede de assistência ou não tinham informações claras sobre a função dos serviços (a que clientela cada um se destinava, qual a diferença entre ambulatório, CAPS etc.).

Assim, essa "rede" acaba sendo caracterizada por um perfil de "fragmentação", tendo como um dos efeitos a descontinuidade nos tratamentos. Concordamos com as colocações de Campos (2000), ao apontar que o princípio de hierarquização representou um entrave no campo da saúde mental, pois forçou os serviços a serem classificados em primários, secundários e terciários e ainda em intermediários, delimitando a necessidade de "classificar" crises e tipos de crises: "dessa maneira, a 
hierarquização para a saúde mental é uma dificultadora ao acesso do usuário e deixa a desejar quanto à eficácia do modelo" (CAMPOS, 2000, p. 60). Segundo Alves \& Guljor (2004), a lógica dos encaminhamentos, caricaturados no sistema de referência e contra-referência, gerou o que sugerem chamar de "uma assistência partida”. Segundo os autores, esta lógica tende à destituição de vínculo e à desresponsabilização, o que fica expresso na fala seguinte:

aqui mesmo a gente vê o quanto a gente não tem esse pensamento, esse trabalho de rede, porque daí o paciente fica na internação, no ambulatório, na consulta individual e parece que não é... É meu, é teu, é de fulano, não é, entende, vai deixando de um pro outro, parece que não é responsabilidade (profissional C).

Outro resultado de nossa pesquisa é que nos casos em que uma rede de trabalho se efetivou entre os trabalhadores dos serviços de saúde/saúde mental, ela assumiu um caráter informal, com uma perspectiva individual e não-institucional, como expressam as falas seguintes:

se a gente não tem uma relação direta com a profissional que está lá (nesse outro serviço) esse paciente se perde (gestor 1).

por exemplo, lá tem uma enfermeira que fez conosco a formação em saúde mental. Então ela liga: "vou levar paciente lá na emergência, vou acompanhar". Nós temos uma enfermeira que trabalha no CAPS daqui também. Então essa coisa "a fulana está em crise, vamos tentar internar” (profissional C).

Nesse sentido, os critérios que passam a dar suporte à constituição da rede (seus fluxos, encontros, agenciamentos) são diversos em relação ao que determina a política oficial, expressa em leis (BRASIL, 1990), manuais (RS, 2002) e no plano de saúde mental de Santa Maria (SES-Santa Maria, 2003). A política oficial preconiza a referência e contra-referência de usuários, tendo em vista a disposição dos serviços de saúde mental em uma rede regionalizada e hierarquizada. No entanto, encontramos critérios de circulação de usuários que não seguem a lógica hierarquizada, sendo baseados nos vínculos afetivos e contatos informais entre os trabalhadores de diferentes serviços. Existe uma percepção entre os trabalhadores de que a política oficial se baseia em um modelo ideal, onde existiria uma proporção adequada de serviços/ população e onde os serviços funcionariam em condições ideais. Porém, no cotidiano esse modelo não encontra condiçôes de ser implementado. Como exemplo de condição não-ideal, cita-se a fila de espera para o acesso ao ambulatório de saúde mental e a 
existência de um número menor de serviços especializados em saúde mental do que o previsto pela macropolítica. Em relação a este último aspecto, cabe apontar que o mesmo é inerente ao processo de Reforma Psiquiátrica, tendo em vista que a substituição da lógica hospitalocêntrica pela lógica da rede de cuidados não é imediata, ocorrendo através de um processo gradual.

Outro aspecto observado é que a burocratização e a dificuldade de acesso aos serviços oficiais da rede pública de assistência em saúde mental acabam alimentando uma espécie de rede paralela, composta por serviços privados, Clínicas-Escola de Psicologia (vinculadas à Universidade Federal de Santa Maria e ao Centro Universitário Franciscano), fazendas terapêuticas e, principalmente, os serviços de internação, que acabam sendo cotidianamente pressionados por ordens judiciais de internação.

[...] bastante ordem judicial. Bastante. Vem internando, e daí às vezes pede avaliação para internação, às vezes decreta que é para internar e há uma combinação aqui que é que interne! Para não se incomodar, porque há uma queixa de que os médicos já tiveram que responder processo por não ter internado (profissional C).

[...] tu encaminha para onde? Então tem sido difícil, até as pessoas gastam dinheiro, tem que pagar consulta, usam medicação, daí depende muito de ter ou não condiçōes para fazer o tratamento. [...] E daí tu fica, "procura alguém, conversa com o fulano, vamos pensar, vamos atrás, liga para o fulano, que atende particular, quem sabe negocia, com o dinheiro", e assim vai. Vai intermediando esse tipo de coisa (profissional C).

Além dos serviços já mencionados, podemos citar outras instâncias que atravessam a constituição da rede de atenção em saúde mental: o Poder Judiciário, abrigos para crianças e adolescentes, serviços de assistência social, a polícia e os bombeiros - muitas vezes chamados para atender situações de crise. Dessa maneira, os serviços envolvidos no processo de produção de saúde não se limitam a uma vinculação estatal ou de caráter público, assim como não se limitam ao âmbito intra-setorial da saúde.

\section{Saúde mental na atenção básica: descentralização ou transferência de responsabilidade?}

A partir de 2004, uma nova estratégia começou a ser delineada para dar conta da demanda crescente: a saúde mental na atenção básica. Na seguinte fala de um gestor, alguns motivos são apontados: 
E até porque está se trabalhando muito, investindo muito, e está se centrando todos esforços desta gestão na atenção básica. E a atenção básica a gente só consegue vê-la junto da comunidade, nas unidades básicas, o mais próximo das pessoas possível. E a identificação que a gente está fazendo, e também já partiu dos próprios profissionais, os próprios trabalhadores de saúde mental já levantaram também essa necessidade. Que começa a se perguntar hoje: no momento em que um usuário nosso aqui do CAPS der alta, eu vou referendar ele para quem? Porque a referência fica o serviço. E aí eles mesmos começaram a perceber, os trabalhadores, que precisava ser investido muito na rede de atenção básica do município para estar dando essas respostas (gestor 1).

Esse investimento na atenção básica é caracterizado principalmente pela implantação das equipes do Programa Saúde da Família (PSF) a partir de março de 2004. Nas falas do gestor 1, a nova lógica é baseada nos princípios e práticas de acolhimento, formação de vínculo, responsabilidade, resolutividade e atendimento humanizado. A avaliação que os participantes da Comissão de Saúde Mental fizeram é de que os PSFs apresentam um funcionamento mais adequado em relação às unidades sanitárias tradicionais. Enquanto nas primeiras se identificou maior potencialidade na realização de parcerias, trabalhos conjuntos etc., as segundas são apontadas como empecilhos, sendo comuns falas como "o que a gente conseguir é lucro". A partir de levantamentos realizados em alguns serviços especializados, constatou-se também um aumento nos encaminhamentos recebidos das equipes de PSF: "E os PSFs são incríveis, é geral, são os que mais estão mandando. Se tu olhar a última planilha, agora é só PSF, são os que mais mandam” (profissional D).

O motivo alegado é o bom funcionamento do PSF e o "rastreamento" realizado a partir das visitas domiciliares. É preciso apontar que a aproximação com atenção básica foi mais uma tentativa de enfrentamento da crescente demanda, sugerindo dificuldades do modelo técnico-assistencial e não a implantação do processo de descentralização em saúde mental. A descentralização implica uma redefinição do sistema local e, principalmente, a definição ou recuperação de novos atores sociais, com potencial para gerar inovação e criação. A discussão sobre a descentralização da atenção em saúde mental passou a ocorrer no final de 2004:

E aí a gente começou essa discussão final do ano passado, não é?, com os trabalhadores de saúde mental assumindo este compromisso de trabalhar na comunidade, nas unidades básicas, no reconhecimento de território, que eu acho uma coisa fundamental (gestor 1). 
Tendo em vista fatores como a fragmentação estabelecida entre os serviços e a desvinculação dos serviços especializados em relação ao território dos usuários, em novembro de 2004 tentou-se formar uma comissão de trabalhadores em saúde mental com trabalhadores dos CAPS, do ambulatório, que teria o objetivo de reconhecer o território junto aos PSFs. No entanto, esse trabalho não ocorreu da forma esperada, "porque sempre tinha alguém que não podia ir em função dos horários” (Diário do pesquisador, 22/06/2005).

Uma nova iniciativa surgiu a partir da gestão, que convocou uma reunião com os representantes dos serviços de atenção básica, dos serviços de saúde mental e das universidades (UFSM, ULBRA e UNIFRA). Dessa reunião surgiu a idéia de constituir uma comissão: "uma comissão pra gente estar pensando como é que nós vamos montar, como é que nós vamos construir essa rede" (gestor 1).

A Comissão Municipal de Saúde Mental (CMSM) reuniu-se pela primeira vez no final de maio de 2005, momento em que teve início esta pesquisa. Foi composta por gestores da Secretaria Municipal de Saúde, professores universitários, representantes dos serviços especializados de saúde mental e representantes dos serviços de atenção básica. $\mathrm{O}$ objetivo da comissão foi propiciar um espaço conjunto de discussão e formulação de estratégias de articulação dessa rede. A principal estratégia delineada foi a construção de um processo de capacitação em saúde mental para a atenção básica. Essa capacitação seria feita por regiôes (norte, sul, oeste, leste, centro), sendo a região norte a primeira. Em função disso, até o momento acompanhado pela pesquisa (final do mês de setembro de 2005), a atenção básica foi representada apenas pelos serviços localizados na região norte (2 PSFs e 2 Unidades Sanitárias).

Entre os objetivos da capacitação, podemos citar: sensibilizar os profissionais para uma escuta mais atenta, trabalhar questôes de estigma e preconceito, apresentar os serviços existentes no município e a que clientela cada um se destina - a fim de melhor instrumentalizá-los para trabalhar com estes casos ou fazer encaminhamentos. Durante o planejamento do processo de capacitação, emergiram ambigüidades do sistema, constatando-se a existência de uma "política oficial", de como deveria funcionar o sistema; e uma política "extra-oficial", de como o sistema é articulado nas práticas cotidianas. Surgiam questōes como "de que adianta apresentar os serviços e na hora que o encaminhamento for feito não tiver vaga?".

A partir de nossa perspectiva metodológica, que supõe o pesquisador como interventor no processo acompanhado, trabalhamos no sentido de problematizar 
a noção de "encaminhamento" - muitas vezes expresso em termos de "manda pra cá", "manda pra lá", configurando a "empurroterapia" - e vislumbrar a possibilidade de trabalho conjunto, a partir de práticas intercessoras, com base em experiências que apontam para essa possibilidade (JATENE et al., 2002; AMARANTE, 1995).

Nesse sentido, tensionamos para que a mera capacitação se tornasse um processo de educação permanente, e que após o processo de capacitação (caracterizado por cinco encontros nos quais seriam realizadas atividades, discussões etc.) se estabelecesse um ou dois profissionais de referência para algumas unidades, para que os profissionais pudessem estabelecer vínculo e trabalhar em conjunto, a partir das emergências cotidianas de cada serviço.

Oliveira (2004) aponta a necessidade de um verdadeiro diálogo entre os profissionais de saúde "geral”, os clínicos e especialistas "do corpo" e os profissionais "psi”, os da "saúde mental". Segundo o autor, para que uma atenção integral seja efetivada, é necessário acabar com a dicotomia que estabelece as Unidades Básicas de Saúde como "centros de atenção do corpo" e os CAPS como "Ambulatórios de Saúde Mental”. A atual política de descentralização da atenção à saúde mental para a atenção básica no município de Santa Maria vem ao encontro dessa proposta. Esta dicotomia, assim como a dimensão do preconceito e estigma, muitas vezes é apresentada como uma realidade nos serviços:

[...] mas a nível de unidade básica, das pessoas que têm o seu cotidiano somente lá, as pessoas não tem essa visão de saúde mental, por isso eu tenho insistido nessa coisa de capacitar [...] eu acho que a gente pode mudar esse nome de capacitação, mas de sensibilização e de que as pessoas consigam fazer esse processo de estar olhando a saúde mental com uma outra visão (profissional B).

Que até hoje a prática é: chegou alguém com transtorno, com alguma dificuldade, já é encaminhada direto ao serviço, que é o ambulatório (gestor 1).

Aí assumi na prefeitura e fui lá para o Itararé. Eu tentava aproximar os pacientes do Itararé, os psicóticos, e fazer alguns agendamentos. Foi quando eu ouvi isso que "lá não era um hospital psiquiátrico, era uma unidade básica (profissional A).

[...] os próprios profissionais não se sentem capazes de dar conta das questões ligadas à saúde mental. Sempre existe aquele estigma, saúde mental é uma coisa meio complicada, o clínico tem muita dificuldade na prescrição, no acompanhamento daquele paciente (gestor 1). 
O processo de "descentralização" da saúde mental para a atenção básica passou a ocorrer não só a partir da constituição da Comissão de Saúde Mental e da construção e efetivação do processo de capacitação. Antes mesmo desse processo, algumas práticas já vinham sendo efetivadas, consistindo no "envio" de usuários dos serviços especializados para atenção básica:

\begin{abstract}
a gente começou há dois meses, e como nossos pacientes saíram com todas as receitas, os que deram alta, a gente não conseguiu ver uma repercussão lá fora ainda, que eles devem começar agora no mês de outubro, ir procurar os PSFs, unidades sanitárias. Que eles vão ficar sem receita, que eles vão ter que consultar, eles vão ter que ir lá. É isso que vai começar, daí a gente vai ter uma avaliação maior (profissional D).
\end{abstract}

Nesse sentido, a descentralização é entendida como o deslocamento dos usuários dos serviços especializados para a atenção básica, num movimento de transferência de responsabilidade.

\title{
Conclusões
}

A noção de rede encontrada remete aos princípios da Reforma Psiquiátrica enquanto um conjunto de serviços substitutivos - e aos princípios da reforma sanitária presentes no SUS - que estabelece a hierarquização dos serviços e ações em saúde, assim como um fluxo de usuários a partir do mecanismo de referência e contra-referência. Observamos, entretanto, que a classificação dos serviços substitutivos nos níveis hierárquicos do SUS, assim como a lógica da referência e contra-referência, acabam propiciando a destituição de vínculo entre profissionaisusuários, a fragmentação da atenção, o enrijecimento e burocratização do acesso e dos fluxos de usuários pelos serviços. Como aponta Cecílio (2004), a lógica da hierarquização auxilia o planejamento e gestão dos sistemas de saúde. Porém, nem sempre corresponde ao cotidiano dos serviços de saúde e dos usuários, já que os serviços de saúde nem sempre funcionam em condiçôes ideais, assim como o fluxo hierarquizado nem sempre faz sentido para o usuário.

Em oposição a essa lógica burocrática, encontramos também resultados que apontam conexões realizadas no cotidiano dos processos de trabalho que transcendem a lógica da referência e contra-referência e da hierarquização. Essas outras conexões são guiadas por vínculos afetivos entre profissionais de diferentes 
serviços, o que acaba facilitando a comunicação, troca de informações e continuidade do tratamento do usuário, mesmo quando ocorre o encaminhamento.

Constatamos ainda avanços no processo de constituição de uma rede de saúde mental, considerando a implantação de novos serviços e ações substitutivas, incluindo a atenção básica, com conseqüente ampliação do acesso à atenção em saúde mental dentro de um modelo substitutivo à internação em hospital psiquiátrico.

Apesar desses avanços, apontamos a necessidade de problematizar a política de descentralização da saúde mental para a atenção básica, promovida através de uma transferência de responsabilidade, ao invés de seu compartilhamento. Consideramos que o encaminhamento de usuários dos serviços especializados para a atenção básica e o processo de capacitação são insuficientes para a efetivação de um processo de descentralização, tendo em vista o caráter fragmentador do primeiro e a pontualidade do segundo.

Como alternativa, apontamos a necessidade de delimitação de profissionais de referência dos serviços especializados em relação à atenção básica, capazes de fornecer suporte contínuo através de ações de educação permanente, supervisões e atendimentos conjuntos - constituindo a lógica do apoio matricial.

\section{Referências}

ALVES, D. S.; GULJOR, A. P. O cuidado em saúde mental. In: PINHEIRO, R.; MATTOS, R. A. de. (org). Cuidado: as fronteiras da Integralidade. Rio de Janeiro: Abrasco, 2004. p. 221-240.

AMARANTE, P. (Coord.). Loucos pela vida: a trajetória da reforma psiquiátrica no Brasil. Rio de Janeiro: Fiocruz, 1995.

O homem e a serpente: outras histórias para a loucura e a psiquiatria. Rio de Janeiro:

Fiocruz, 1996.

BENEVIDES, R. A Psicologia e o Sistema Único de Saúde: quais interfaces? Psicologia e Sociedade, v. 17 , n. 2 , p. $21-25,2005$.

BRASIL. Ministério da Saúde. Saúde Mental no SUS: os Centros de Atenção Psicossocial. Brasília, DF, 2004a.

. Ministério da Saúde. Residências terapêuticas: o que são, para que servem. Brasília: Ministério da Saúde, 2004b.

. Relatório Final da II Conferência Nacional de Saúde Mental. Brasília: MS, 1992.

. Lei Federal no . 8.080, de 19 de setembro de 1990. Dispõe sobre as condiçôes para a promoção, proteção e recuperação da saúde, a organização e o funcionamento dos serviços 
correspondentes e dá outras providências. Disponível em: <http://www.planalto.gov.br/ccivil/ leis/L8080.htm>. Acesso em: 28 out. 2005.

CAMPOS, F. C. B. O modelo da reforma psiquiátrica brasileira e as modelagens de São Paulo, Campinas e Santos. 2000. 177p. Tese (Doutorado em Saúde Coletiva) - UNICAMP, Campinas, 2000.

CABRAL, B. et al. Estação Comunidade. In: JATENE, A. D. et al. (Org.). SaudeLoucura: saúde mental e saúde da família, n. 7. São Paulo: Hucitec, 2002. p. 137-153.

CASÉ, V. Saúde mental e sua interface com o Programa de Saúde da Família: quatro anos de experiência em Camaragibe. In: JATENE, A. D. et al. (Org.). SaudeLoucura: saúde mental e saúde da família, n. 7. São Paulo: Hucitec, 2002. p. 121-135.

CARVALHO, S. R.; CAMPOS, G. W. de S. Modelos de Atenção à Saúde: a organização de equipes de referência na rede básica da Secretaria Municipal de Saúde de Betim, Minas Gerais. In: BRASIL/ Ministério da Saúde. VER-SUS Brasil: caderno de textos. Brasília, 2004. p. 138-153.

CECILIO, L. C. de O. Modelos Tecno-assistenciais em Saúde: da pirâmide ao círculo, uma possibilidade a ser explorada. In: BRASIL/Ministério da Saúde. VER-SUS Brasil: caderno de textos. Brasília, 2004. p. 90-106.

CRASOVES, M. L. R. O percurso da loucura em Santa Maria: Comunidade - Instituição Sociedade. Revista de Saúde Mental Coletiva, Bagé-RS, ano II, n. 2, p. 47-50, 2005.

GOLDBERG, J. Clínica da psicose: um projeto na rede pública. Rio de Janeiro: Te Corá, 1996

GONÇALVES, P. L. A unidade de referência e a equipe volante. In: JATENE, A. D. et al. (Org.). SaudeLoucura: saúde mental e saúde da família, n. 7. São Paulo: Hucitec, 2002. p. 109-116.

JATENE, A. D. et al. (Org.). SaudeLoucura: saúde mental e saúde da família, n. 7. São Paulo: Hucitec, 2002.

MELMAN, J. Família e doença mental: repensando a relação entre profissionais de saúde e familiares. São Paulo: Escrituras, 2001.

MORIN, A. Pesquisa-ação integral e sistêmica: uma antropopedagogia renovada. Rio de Janeiro: DP\&A, 2004.

NICÁCIO, F., AMARANTE, P., BARROS, D. D. Franco Basaglia em terras brasileiras: caminhantes e itinerários. In: AMARANTE, P. (Org.). Archivos de Saúde Mental e atenção psicossocial. v. 2. Rio de Janeiro: Nau, 2005. p. 195-214.

OLIVEIRA, W. F. de. Apresentação. Dynamis Revista Tecno-Cientifica. Blumenau, v. 12, n. 46, p. $1,2004$.

RIO GRANDE DO SUL. Guia de Serviços de Saúde Mental: cuidar sim, excluir não. Porto Alegre: SES, 2002. 
. Lei Estadual no 9.716, de 7 de agosto de 1992. Dispõe sobre a reforma psiquiátrica no Rio Grande do Sul, determina a substituição progressiva dos leitos nos hospitais psiquiátricos por rede de atenção integral em saúde mental, determina regras de proteção aos que padecem de sofrimento psíquico, especialmente quanto às internações psiquiátricas compulsórias, e dá outras providências. Disponível em: http://www.inverso.org.br/index.php/content/view/4442.html. Acesso em: 20 set. 2005.

ROTELLI, F. Superando o manicômio - o circuito psiquiátrico de Trieste. In: AMARANTE, P. (Org.). Psiquiatria Social e Reforma Psiquiátrica. Rio de Janeiro: Fiocruz, 1994. p. 149-170.

SECRETARIA DE SAÚDE DE SANTA MARIA. Plano de saúde mental. Santa Maria: SMS, 2003.

SOUZA, A. C. de.; VASCONCELLOS, M. M.; AMARANTE, P. Novas perspectivas em atenção psicossocial. Dynamis Revista Tecno-Cientifica. Blumenau, v. 12, n. 46, p. 23-28, 2004.

VASCONCELOS, E. M. Mundos paralelos, até quando? Os psicólogos e o campo da saúde mental pública no Brasil nas duas últimas décadas. Revista Mnemosine: Psicologia em Histórias, Rio de Janeiro, n. 0. 1998, s/p.

\section{Notas}

${ }^{1}$ Dados do Instituto Brasileiro de Geografia e Estatística (IBGE), referente ao Censo/2000. Disponível em: <www.ibge.gov.br/cidadesat/topwindow.htm?1>. Acesso em: 4 jun. 2008

${ }^{2}$ Dados da Fundação de Economia e Estatística, referente ao ano de 2005. Disponível em: <http:// www.fee.tche.br/sitefee/pt/content/resumo/pg_municipios_detalhe.php?municipio=Santa+Maria $>$ Acesso em: 4 jun. 2008. 


\section{Abstract}

Building a process of mental health care network: challenges and potentialities of the Psychiatric Reform

This work aims to investigate how the mental health care network has been built in Santa Maria, State of Rio Grande do Sul, focusing on its articulation with the ideals of the Psychiatric Reform and the SUS. The methodology was the Systemic and Integral Action Research. The research subjects were managers and workers of the municipal Health Department. Data collection was carried out through participant observation in Mental Health Commission meetings, as well as in interviews with informants. Data points out that the reference and counter-reference system is little effective and that the working processes are fragmented (causing treatment discontinuity, lack of professional responsabilization etc). Strategies towards the construction and articulation of the network, agreed among health managers and workers, involve the implantation of substitute services, implementation of a Mental Heath Care Commission and the process of training capabilities regarding mental heath care towards basic health care. Yet, we found a series of strategies grounded on the routine of the working processes, determining an informal network - not foreseen by health macro-politics. Hereby, we problematize some principles that underline the network organization concerning SUS and the Psychiatric Reform, as well as the ambiguous effects of the way the network construction and articulation are accomplished.

> Key words: Network; SUS; Psychiatric Reform; mental health. 